\title{
The Role of Frizzled 3 and Frizzled6 in Neural Tube Closure and in the Planar Polarity of Inner-Ear Sensory Hair Cells
}

\author{
Yanshu Wang, ${ }^{1,2 *}$ Nini Guo, ${ }^{1 *}$ and Jeremy Nathans ${ }^{1,2,3}$ \\ ${ }^{1}$ Department of Molecular Biology and Genetics, ${ }^{2}$ Howard Hughes Medical Institute, and ${ }^{3}$ Departments of Neuroscience and Ophthalmology, Johns \\ Hopkins University School of Medicine, Baltimore, Maryland 21205
}

In the mouse, Frizzled3 (Fz3) and Frizzled6 (Fz6) have been shown previously to control axonal growth and guidance in the CNS and hair patterning in the skin, respectively. Here, we report that Fz3 and Fz6 redundantly control neural tube closure and the planar orientation of hair bundles on a subset of auditory and vestibular sensory cells. In the inner ear, Fz3 and Fz6 proteins are localized to the lateral faces of sensory and supporting cells in all sensory epithelia in a pattern that correlates with the axis of planar polarity. Interestingly, the polarity of Fz6 localization with respect to the asymmetric position of the kinocilium is reversed between vestibular hair cells in the cristae of the semicircular canals and auditory hair cells in the organ of Corti. Vangl2, one of two mammalian homologs of the Drosophila planar cell polarity (PCP) gene van Gogh/Strabismus, is also required for correct hair bundle orientation on a subset of auditory sensory cells and on all vestibular sensory cells. In the inner ear of a Vangl2 mutant (Looptail; LP), Fz3 and Fz6 proteins accumulate to normal levels but do not localize correctly at the cell surface. These results support the view that vertebrates and invertebrates use similar molecular mechanisms to control a wide variety of PCP-dependent developmental processes. This study also establishes the vestibular sensory epithelium as a tractable tissue for analyzing PCP, and it introduces the use of genetic mosaics for determining the absolute orientation of PCP proteins in mammals.

Key words: inner ear; hair bundle orientation; neural tube closure; Looptail; Vangl2; tissue polarity

\section{Introduction}

The high degree of anatomic complexity observed throughout the animal kingdom implies the existence of sophisticated signaling systems to coordinate cellular, tissue, and body architecture. The present study focuses on one system that coordinates the orientation of locally asymmetric structures within a plane, a phenomenon referred to as tissue or planar cell polarity (PCP). In particular, this study focuses on PCP in the vertebrate inner ear, where the hair bundles of auditory and vestibular sensory cells are precisely oriented with respect to the surrounding bony structures and the axes of the skull.

Genetic studies of PCP began in Drosophila and have led to the identification of 8-10 "core PCP genes" that are required for the orientation of cuticular hairs and bristles and the chiral orientation of photoreceptors within each ommatidial unit (Gubb and Garcia-Bellido, 1982; Adler, 2002; Strutt, 2003; Klein and Mlodzik, 2005). Frizzled ( $F z)$, the first PCP gene to be defined molecularly, codes for a seven-pass transmembrane protein

Received Nov. 2, 2005; revised Jan. 11, 2006; accepted Jan. 11, 2006.

This work was supported by the Howard Hughes Medical Institute. We thank Alain Dabdoub, Hakim Hiel, and Amir Rattner for advice; John Williams and Phil Smallwood for genotyping and molecular biology support; Tom Rotolo and Carol Cooke for assistance with electron microscopy; Jichao Chen for statistical analyses; Charles Hawkins for performing in vitro fertilizations and embryo aggregation; Xiaowei Lu and Marc Tessier-Lavigne for sharing the $L p$ mouse line; David Rini for drawing Figure 2; and Amir Rattner for helpful comments on this manuscript.

*Y.W. and N.G. should be considered co-first authors.

Correspondence should be addressed to Dr. Jeremy Nathans, 805 Preclinical Teaching Building, 725 North Wolfe Street, Johns Hopkins University School of Medicine, Baltimore, MD 21205. E-mail: jnathans@jhmi.edu. DOI:10.1523/JNEUROSCI.4698-05.2005

Copyright $\odot 2006$ Society for Neuroscience $\quad$ 0270-6474/06/262147-10\$15.00/0
(Vinson et al., 1989). Subsequent work identified numerous $\mathrm{Fz}$ homologs throughout the animal kingdom and showed that they serve as receptors for Wnts (Bhanot et al., 1996; Wang et al., 1996). Wnt signaling through the "canonical" signaling pathway is critical for diverse developmental processes (Logan and Nusse, 2004), but at present there is no evidence for Wnt signaling in Drosophila PCP (Klein and Mlodzik, 2005) and only indirect evidence for Wnt signaling in vertebrate PCP (Dabdoub et al., 2003).

In mammals, $\mathrm{Fz}$ genes have been implicated in a variety of developmental processes, including several that involve the nervous system. $\mathrm{Fz} 3$ is required for axonal outgrowth and guidance in the CNS (Wang et al., 2002, 2006; Lyuksyutova et al., 2003); Fz4 is required for the growth of retinal capillaries, the development of the esophagus, the survival of cerebellar neurons, and the maintenance of the vasculature within the cochlea (Wang et al., 2001; Xu et al., 2004); Fz5 is required for yolk sac and placental angiogenesis and for Paneth cell maturation in intestinal crypts (Ishikawa et al., 2001; van Es et al., 2005); and Fz6 controls hair patterning (Guo et al., 2004). Among these phenotypes, only hair patterning seems clearly analogous to the PCP defects defined in Drosophila. However, PCP appears to be involved in other developmental processes in vertebrates as judged by the developmental processes that are perturbed by defects in vertebrate homologs of the Drosophila PCP genes Van Gogh (Vang)/Strabismus, Flamingo/Starry Night, and Disheveled (Copp et al., 2003; Torban et al., 2004; Dabdoub and Kelley, 2005; Klein and Mlodzik, 2005). These processes include the polarized cell movements required 
for convergent extension during gastrulation in frogs and fish, neural tube and eyelid closure in mammals, and the correct orientations of hair bundles in auditory sensory cells.

As noted above, $\mathrm{Fz} 3-/-$ mice and Fz6-/ - mice display distinct phenotypes in the brain and skin, respectively. However, we suspected that Fz3 and Fz6 might show some redundancy based both on previous observations that Drosophila $\mathrm{Fz}$ and $F z 2$ exhibit substantial redundancy (Kennerdell and Carthew, 1998; Bhanot et al., 1999; Chen and Struhl, 1999) and on the similarity in sequence and intronexon structure that places $F z 3$ and $F z 6$ together on a distinct evolutionary branch within the $F z$ family. In the present work, we confirm this idea by showing that $F z 3$ and $F z 6$ function redundantly to control neural tube closure and the orientation of a subset of auditory and vestibular sensory cells. We also describe the asymmetric localization of these Fz proteins in inner-ear sensory epithelia and the loss of that localization caused by mutation of Vangl2.

\section{Materials and Methods}

Inner-ear dissection. Temporal bones were fixed in $2 \%$ paraformaldehyde at room temperature for $1 \mathrm{~h}$, followed by three washes in PBS. Bone fragments were carefully removed to expose the cochlea, utricle, saccule, and cristae. The stria and the tectorial membranes were removed from the cochleas to reveal the organ of Corti, and openings were made in the nonsensory ep-

ithelia near the utricle and saccule and in the ampula of the semicircular canals. With the sensory epithelia thus exposed, the entire sample was subject to immunostaining. At this stage, the samples could be manipulated by holding the remaining bone. After immunostaining, sensory epithelia were gently lifted from the remaining bone and viewed as flat mounts.

Immunostaining of inner-ear sensory epithelia. Dissected tissues were incubated in PBS with 10\% normal goat serum and $0.3 \%$ Triton X-100 (blocking solution) at room temperature for $1 \mathrm{~h}$, followed by overnight incubation in primary antibodies diluted in blocking solution at $4^{\circ} \mathrm{C}$. Tissues were washed in PBS with $0.3 \%$ Triton X-100 at room temperature for $6 \mathrm{~h}$, followed by overnight incubation at $4^{\circ} \mathrm{C}$ with fluorescent secondary antibodies diluted in blocking solution. Tissues were then washed in PBS with $0.3 \%$ Triton X-100 at room temperature for $6 \mathrm{~h}$ before being flat mounted in Fluoromount-G.

Antibodies. Commercial antibodies were from the following sources: mouse anti-acetylated tubulin, clone 6-11B-1 (T6793; Sigma, St. Louis, MO); chicken anti- $\beta$-galactosidase (ab9361; Abcam, Cambridge, MA); Texas Red phalloidin (T7471; Molecular Probes, Eugene, OR); Alexa 647 phalloidin (A22287; Molecular Probes); Alexa 488 goat anti-rabbit IgG (A11008; Molecular Probes); Alexa 594 goat anti-rabbit IgG (A11012; Molecular Probes); Alexa 488 goat anti-mouse IgG (A11001; Molecular Probes); Alexa 488 goat anti-chicken IgG (A11039; Molecular Probes). Other antibodies were prepared as follows. (1) Rabbits were immunized with the C-terminal 120 aa of mouse Fz3 fused to the T7 Gene10 protein (using the pGEMEX expression plasmid). Antisera were affinity purified using the same C-terminal 120 aa of $\mathrm{mFz} 3$ fused to the maltose-binding protein blotted onto nitrocellulose membranes. These antibodies work well for immunostaining of tissue but less well for immunoblots. (2) Rabbits were immunized with a synthetic peptide corresponding to the
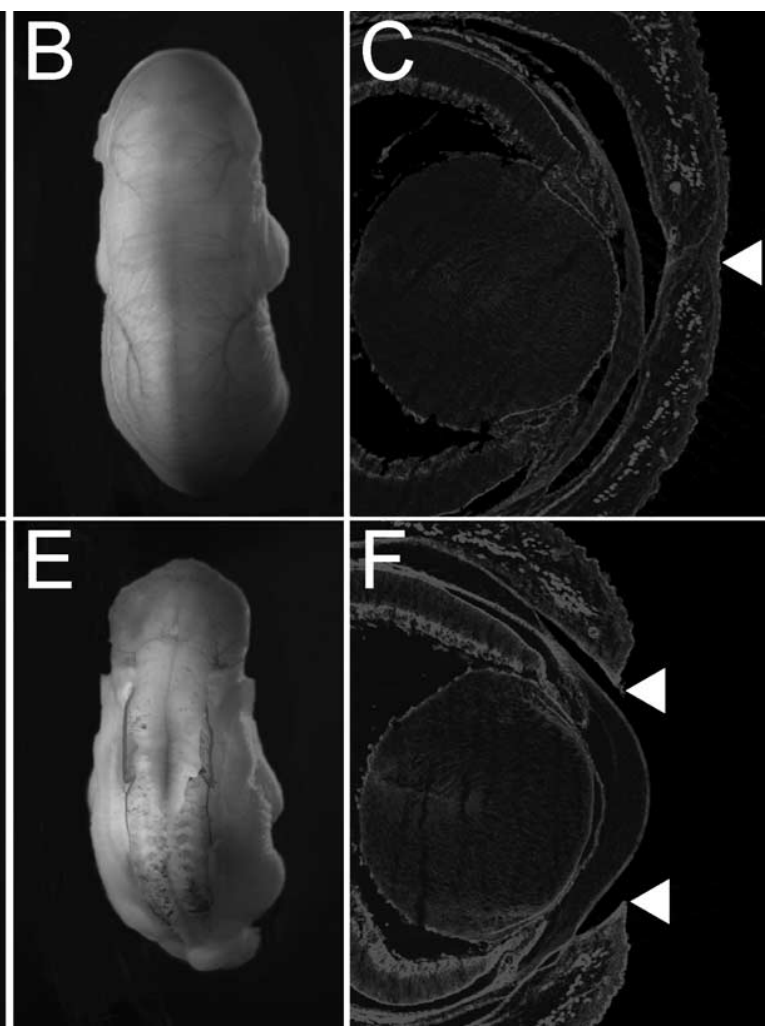

Figure 1. External morphology of $F z 3-/-; F z 6-/-$ mice at E18. A, B, D, E, A fully open neural tube (craniorachischisis) is observed in nearly all $F z 3-/-; F z 6-/-$ embryos. The neural tube in $F z 3+/+; F z 6-/-$ and $F z 3+/-; F z 6-/-$ littermates is eyelids $(\boldsymbol{F})$. The eyelids remain open in $\sim 10 \%$ of $F z 3-/-; F z 6-/-$ late-gestation embryos. Eyelid closure occurs normally in $\mathrm{Fz}_{\mathrm{Z}}+\mathrm{I}+; \mathrm{Fz} 6-\mathrm{l}-$ and $\mathrm{Fz} 3+\mathrm{l}-; \mathrm{Fz} 6-\mathrm{l}-$ littermates.

C-terminal 17 aa of mouse Fz3 cross-linked to BSA. Antisera were affinity purified using the immunizing peptide coupled to Affigel. These antibodies work well for immunoblots but less well for immunostaining of tissue. (3) Rabbits were immunized with a synthetic peptide corresponding to the C-terminal 17 aa of mouse Fz6 cross-linked to BSA (Guo et al., 2004). Antisera were affinity purified using the immunizing peptide coupled to Affigel. These antibodies work well for both immunostaining of tissue and immunoblots.

Tissue preparation for immunoblotting. Inner ears (two inner ears from one animal per sample) were homogenized with a micro-pestle in $100 \mu \mathrm{l}$ of ice-cold lysis buffer (50 mM Tris- $\mathrm{HCl}, \mathrm{pH} 7.5,150 \mathrm{~mm} \mathrm{NaCl}, 1 \mathrm{~mm}$ EDTA, and 1\% NP-40) supplemented with protease inhibitors. The tissue homogenates were further incubated on ice for $10 \mathrm{~min}$, followed by centrifugation at $5000 \times g$ for $5 \mathrm{~min}$ at $4^{\circ} \mathrm{C}$. Dissected brain homogenates were prepared in the same manner with correspondingly larger volumes. Laemmli buffer was added to each supernatant, the samples were incubated at $37^{\circ} \mathrm{C}$ for $10 \mathrm{~min}$, and $20 \mu \mathrm{l}$ was resolved by SDS-PAGE on a $10 \%$ gel. Immunoblots were incubated at $4^{\circ} \mathrm{C}$ overnight in affinity-purified primary antibodies (anti-Fz3, 1:1000; anti-Fz6, 1:300), for $2 \mathrm{~h}$ at room temperature in HRP-conjugated goat anti-rabbit (diluted 1:2500; BioRad, Hercules, CA), and the immunoreactive bands were visualized with the SuperSignal West Pico Substrate (Pierce, Rockford, IL).

Animal husbandry. The Fz3 and Fz6 mutations were maintained on a mixed C57Bl/ $6 \times 129 / \mathrm{SVJ}$ background. The $L p$ line was originally obtained from The Jackson Laboratory (Bar Harbor, ME) (LPT/Le stock). The Fz6 mutation was maintained in the homozygous state (Guo et al., 2004), and the $F z 3$ and $L p$ mutations were maintained in the heterozygous state. $F z 3-/-; F z 6-/-$ and $L p / L p$ embryos were obtained by natural matings between $L p /+$ or between $F z 3+/-; F z 6-/-$ male and female mice, respectively, or via embryo transfer. For embryo transfer, 3 -weekold $F z 3+/-; F z 6-/-$ female mice were primed with pregnant mare's 


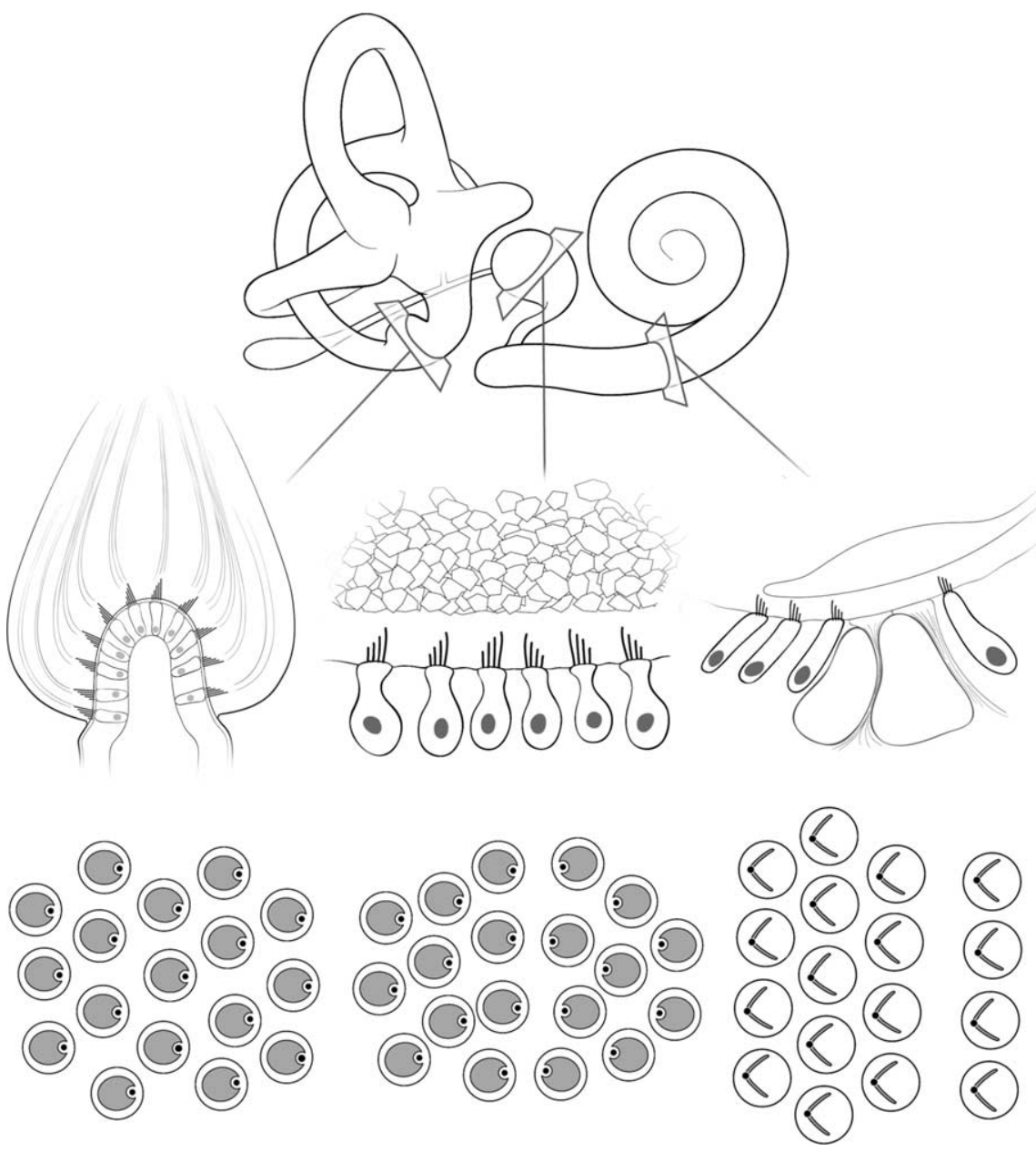

Figure 2. Diagram of the mammalian inner ear and the orientation of sensory hair bundles. Top, Three-dimensional arrangement of the mammalian inner-ear ducts and the locations of sensory epithelia. Center, Cross-sectional views through the principal types of sensory epithelia. Bottom, En face views of these sensory epithelia showing the apical face of the sensory hair cells and the arrangement of hair bundles. The crista (semicircular canal), utricle, and organ of Corti (cochlea) are shown left to right. The saccule closely resembles the utricle, but in the saccule, the hair bundles face away from each other rather toward each other across the equator (Denman-Johnson and Forge, 1999). In the en face view, each kinocilium (-) resides adjacent to a cluster of stereocila. In this view, the stereocilia form a "V" in cochlear hair cells and a disc in hair cells from the utricle, saccule, and cristae.

al., 2001), Dvl1 and Dvl2 (Hamblet et al., 2002; Wang et al., 2005), Scrbl (Murdoch et al., 2003), Celsr1 (Curtin et al., 2003), PTK7 (Lu et al., 2004)].

Although $\mathrm{Fz} 3+/-$ mice and $\mathrm{Fz} 6-/-$ mice are healthy and fertile, Fz3+/-; $\mathrm{Fz6}-\mathrm{/}-$ males show reduced fertility. Dissection of their vas deferens reveals a $>10$ fold reduction in the number of sperm cells, suggesting that $F z 3$ and $F z 6$ may play a redundant role in sperm development and/or endocrine processes that regulate male fertility. Interestingly, we also observed low fertility in males heterozygous for the Lp mutation (a spontaneous mutation in Vangl2) (Strong and Hollander, 1949; Kibar et al., 2001; Murdoch et al., 2001). A recent report of Celsr RNA and protein localization in rat testis further supports the idea that signaling via PCP components plays a role in male fertility (Beall et al., 2005).

\section{Defects in the orientation of hair bundles in the $\mathrm{Fz3}-/-$; Fz6-/- inner ear}

As noted in the Introduction, mutations in any of several PCP genes cause misorientation of hair bundles in cochlear hair cells [Celsr1 (Curtin et al., 2003), Vangl2 and Scrbl (Montcouquiol et al., 2003)]. In our initial survey of $\mathrm{Fz} 3$ and Fz6 loss-offunction phenotypes, no apparent defects in the inner ear were observed in $\mathrm{Fz} 3-\mathrm{/}-$, Fz6-/-, or Fz3+/-;Fz6-/- mice (data not shown). In particular, hair bundle orientations were normal in the organ of Corti, utricle, saccule, and cristae (see Fig. 2 for an overview of inner-ear anatomy). In contrast, $F z 3-/-; F z 6-/-$ inner ears show characteristic defects in hair bundle orientation in the organ of Corti and the

serum and human chorionic gonadotropin, followed by mating to $F z 3+/-; F z 6-/-$ male mice. Fertilized two-cell embryos were transferred to pseudo-pregnant females, and embryonic day 18 (E18) pups were recovered.

Embryo chimeras. WT:Fz6-/- embryo chimeras were generated as described by Guo et al. (2004), except that the wild-type (WT) embryo partner was either C57BL/6 or ICR.

\section{Results}

Defects in neural tube and eyelid closure in

Fz3-/-;Fz6-/- embryos

Fz3-/-;Fz6-/- embryos exhibit craniorachischisis (a fully open neural tube) with nearly $100 \%$ penetrance (Fig. $1 A, B, D, E$ ), and they die within minutes of birth. Like Fz3-/- embryos (Wang et al., 2002), each double mutant embryo also has a curled tail. Approximately $10 \%$ of E18 Fz3-/-;Fz6-/- embryos exhibit unfused eyelids (Fig. 1C,F), which in normal mice fuse at $\sim$ E16 (Findlater et al., 1993). Both neural tube and eyelid closure require the directed migration and proliferation of paired epithelial sheets. As noted in the Introduction, one or both defects have been observed in mice carrying mutations in other homologs of Drosophila PCP genes [Vangl2 (Greene et al., 1998; Murdoch et cristae. Among the four rows of auditory hair cells in the organ of Corti, the inner-hair cells (IHCs) show the most severe orientation defects (Fig. 3). More modest orientation defects are present in the outermost row of outer-hair cells (OHC3), and minimal effects are seen in the inner two rows of outer-hair cells $(\mathrm{OHCl}$ and OHC2). Interestingly, in the $L p / L p$ cochlea, the orientation defect is most severe in $\mathrm{OHC} 3$, although all of the other hair cell layers also show substantial misorientation (Fig. 3). [We note that in the original description of the $L p / L p$ phenotype, the IHC and $\mathrm{OHC} 3$ defects were seen to be more nearly comparable in severity (Montcouquiol et al., 2003).] At the time point examined (E18), hair cells in the WT organ of Corti have very nearly attained their final correct orientations (Dabdoub et al., 2003). The organ of Corti in both $F z 3-/-; F z 6-/-$ and $L p / L p$ mice also exhibits some disorganization in the locations of hair cells within individual rows, frequent ectopic hair cells beyond OHC3 (Fig. 3 ), and an underdeveloped tectorial membrane (data not shown).

Hair bundles in the cristae, saccule, and utricle are longer than those in the organ of Corti, and their stereocilia are arranged in a compact cluster rather than a V-shape. However, the orientation 
of these hair bundles can be determined from the asymmetric insertion of the kinocilium, the single true cilium, which is readily visualized by immunostaining for acetylated tubulin (Fig. 4A-C). During dissection of the vestibular sensory epithelia, the hair bundles are not infrequently broken off, and in these cases, the orientation of the sensory cells can be determined by noting the location of the hole left by the kinocilium in the actin-rich cuticular plate at the apical face of the cells (Fig. 4D-F).

A comparison of WT, Fz3-/-; Fz6-/-, and Lp/Lp vestibular sensory epithelia at E18 shows that WT hair bundles are well oriented, whereas $L p / L p$ hair bundles are severely misoriented in the utricle, saccule, and cristae (Fig. 4G,H, cristae and utricle; saccule, data not shown). In contrast, $F z 3-/-; F z 6-/-$ hair bundles are variably misoriented in the cristae and normally or nearly normally oriented in the utricle (Fig. 4G,H) and saccule (data not shown). In the Fz3-/-;Fz6-/- organ of Corti, utricle, saccule, and cristae, the defects in hair bundle orientation are not associated with any apparent ultrastructural defects in the stereocilia or kinocilium (data not shown), suggesting that the misorientation occurs within the context of an otherwise normally assembled hair bundle. We also note that the $L p$ phenotype in the inner ear appears to be fully recessive, because $L p /+$ inner ears exhibit normal hair bundle orientations in all innerear sensory epithelia (data not shown). The greater severity of the $L p / L p$ phenotype relative to $F z 3-/-; F z 6-/-$ in the vestibular system and the quantitative differences between the $L p / L p$ and $F z 3-/-; F z 6-/-$ phenotypes in the organ of Corti suggest that additional and perhaps partially redundant $F z$ and Vangl family members may also be involved in hair bundle orientation.

\section{Fz3 and Fz6 proteins accumulate asymmetrically in the plane of the inner-ear sensory epithelia}

In Drosophila, genetic and protein-protein interaction experiments show that several PCP proteins are localized asymmetrically in the plane of the epithelium in a mutually interdependent manner, supporting a model in which different subsets of PCP proteins form signaling complexes at the proximal and distal faces of adjacent cells (Usui et al., 1999; Axelrod, 2001; Shimada et al., 2001; Strutt, 2001, 2003; Adler, 2002; Klein and Mlodzik, 2005). Moreover, at least some, and perhaps all, of the proteins within these complexes are further localized to the apical region of each epithelial cell (Usui et al., 1999; Djiane et al., 2005). To define the cellular and subcellular localization of Fz3 and Fz6, we immunostained WT and control Fz3-/- or Fz6-/- embryos with affinity-purified rabbit antibodies raised against synthetic peptides or bacterial fusion proteins corresponding to the $\mathrm{C}$ termini of Fz3 or Fz6. Each antibody appears to specifically recognize its target because (1) immunoblotting of extracts from WT versus the corresponding knock-out embryos reveals a major immunoreactive band of the expected molecular mass only in the WT sample [Fig. 5G, left, shows the result with anti-Fz3 immunoblotting of E18 mouse brain; an analogous immunoblot with
WT

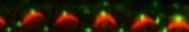

A. $2 \cdot i^{2}+i^{4}$

Asitis

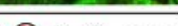

100000

000
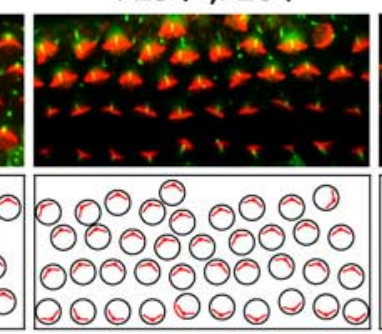

Fz3-/-;Fz6-/-

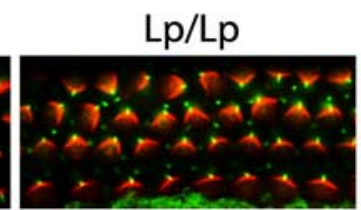
000000000 000000000
00000000
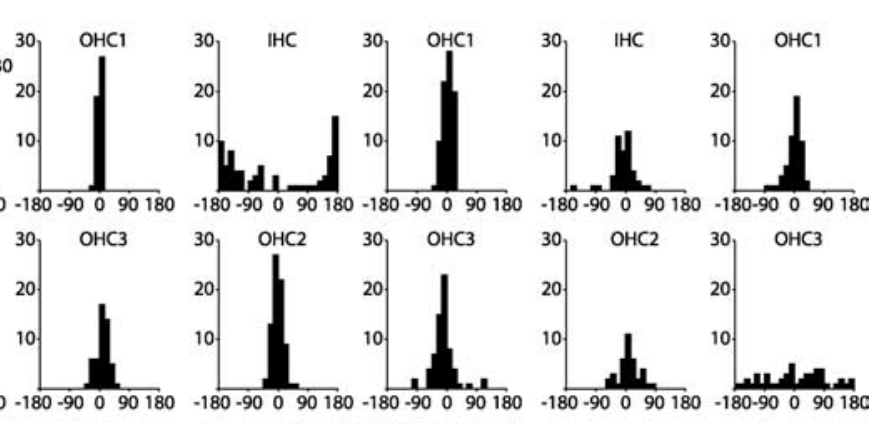

100000000

orientation (degrees)

defects in the organ of Corti in WT, Fz3 - /-;Fz6-/-, and Lp/Lp mice atE18. $A$, Top, Stereocilia labeled with phalloidin (red) and kinocilia labeled with anti-acetylated tubulin (green), near the base of the organ of Corti at E18. Bottom, Diagrams showing the scoring of hair bundle orientation for the images above. $\mathrm{OHC1}$, Inner row of

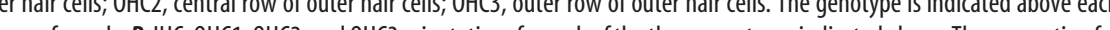
列 WT versus Fz3 - / ; ;Fz6-/-, Fz3 - / -;Fz6-/- versus Lp/Lp. IHC: $5 \times 10^{-5},<2 \times 10^{-16},<2 \times 10^{-16} ;$ OHC1: $1 \times$ $10^{-4}, 2 \times 10^{-5}, 0.2 ; \mathrm{OHC} 2: 3 \times 10^{-5}, 2 \times 10^{-4}, 1 \times 10^{-3} ; \mathrm{OHC} 3: 1 \times 10^{-7}, 4 \times 10^{-6}, 2 \times 10^{-7}$.

anti-Fz6 is shown in the study by Guo et al. (2004), their Fig. 1] and (2) immunostaining of tissue from mice carrying WT versus knock-out alleles of $F z 3$ or $F z 6$ shows localized Fz3 or Fz6 staining in WT but not in $\mathrm{Fz3}-/-$ or Fz6-/- tissues, respectively (Figs. $5 E, F, 6,7$; and data not shown).

The $F z 3$ and $F z 6$ genes are expressed in all sensory hair cells and in many nonsensory epithelial cells in the inner ear, as initially determined by the histochemical localization of a $\beta$-galactosidase reporter that was inserted at each locus (Fig. $5 \mathrm{~A}-$ $D)$. Curiously, at the Fz6 locus, the knocked-in nuclear $\beta$-galactosidase reporter shows variegated expression in cochlear hair cells (Fig. 5D). The variegation could be caused either by the deletion of introns 2 and 3 of the Fz6 gene in the knock-in allele or by the presence of sequences within the $\beta$-galactosidase reporter cassette, but not by the co-inserted PGK-neo marker used for selection in embryonic stem cells, because this segment was removed by Cre-mediated recombination (Guo et al., 2004).

By immunostaining, Fz3 and Fz6 are each present at the cell surface, most likely at the plasma membrane, in both hair cells and supporting cells in the utricle, cristae, and the organ of Corti (Figs. $5 E, F, 6)$. In each of these sensory epithelia, the Fz3 and Fz6 immunostaining patterns are nearly identical to one another in their cellular and subcellular distributions, consistent with their genetic redundancy in inner-ear development. In the organ of Corti, Fz3 and Fz6 are localized to a series of remarkably discrete zones: along the inner (neural) face of the OHCs, the inner face of the IHCs, the entire outer (abneural) face and a discrete zone along the inner face of the pillar cells (supporting cells that lie between IHCs and OHC1s), and along the narrow processes of supporting cells that line the inner face of the IHCs (Figs. 5E, F, 7). 

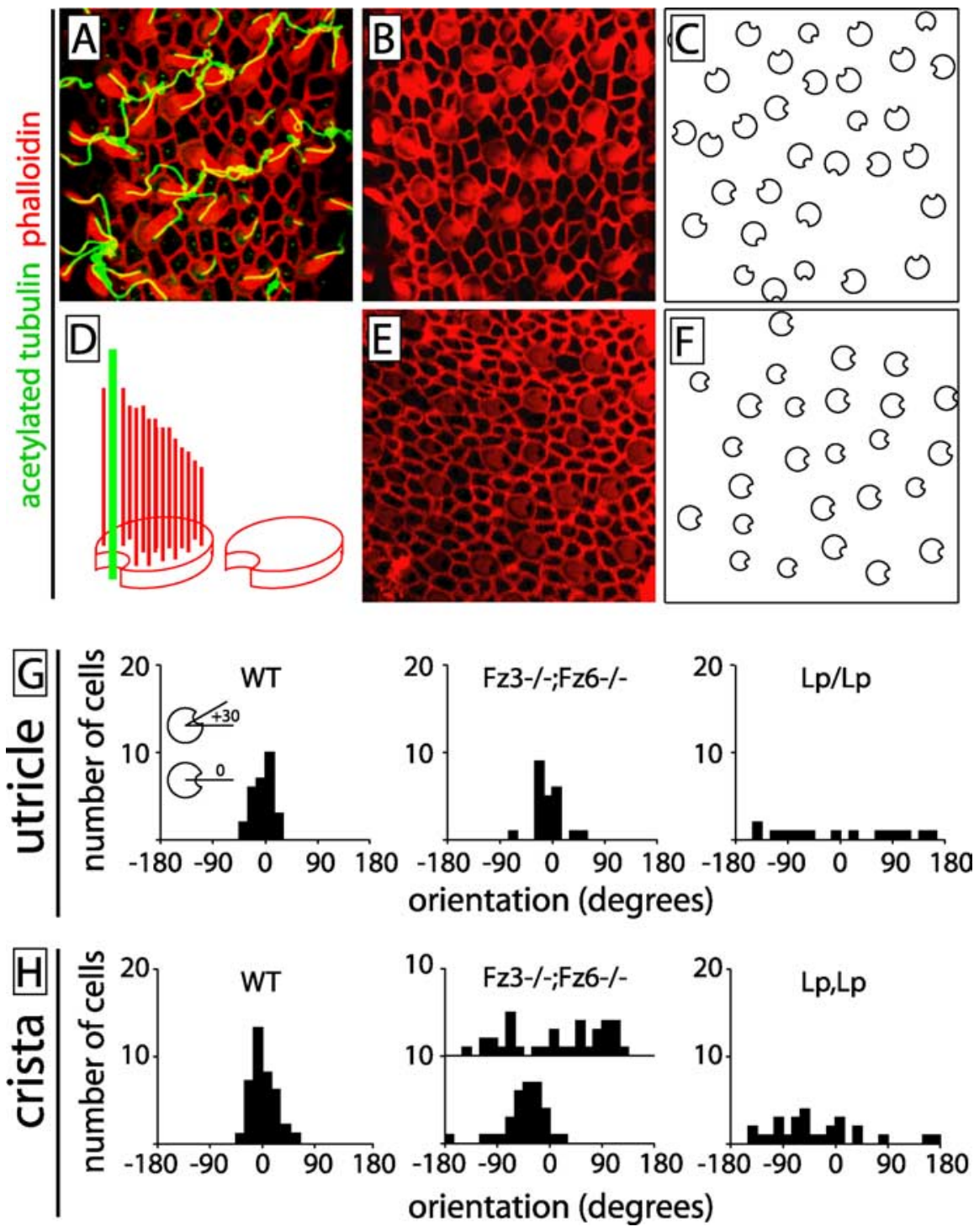

Figure 4. Comparison of defects in hair bundle orientation in WT, Fz3 $-/-; F z 6-/-$, and $L p / L p$ utricles and cristae at E18. $\boldsymbol{A}-\boldsymbol{C}$, Flat-mounted $L p / L p$ crista. $\boldsymbol{A}$, Stereocilia labeled with phalloidin (red) and kinocilia labeled with anti-acetylated tubulin (green) in an optical section immediately above the apical surface of the epithelium. $\boldsymbol{B}$, The same crista, showing only the phalloidin stain with the optical plane just below the apical surface of the epithelium. Within the cuticular plate of each hair cell, a small zone that lacks phalloidin staining marks the site from which the kinocilium projects (compare $\boldsymbol{A}, \boldsymbol{B}$ ). $\boldsymbol{C}, \mathrm{Scoring}$ of hair bundle orientations in $\boldsymbol{A}$ and $\boldsymbol{B}$. D $\boldsymbol{D} \boldsymbol{F}$, The effect of mechanically removing the hair bundle. $\boldsymbol{D}$, Schematic of the intact hair bundle inserted into the cuticular plate (left) and the cuticular plate after the hair bundle has been mechanically removed (right). $\boldsymbol{E}$ Flat-mounted WT utricle labeled with phalloidin after hair bundle removal. $\boldsymbol{F}$, Scoring of hair bundle orientations in $\boldsymbol{E}$. $\boldsymbol{G}, \boldsymbol{H}$ Histograms showing the hair bundle orientations for the indicated genotypes. The convention for angular measurements of hair bundles is shown in the histogram for the WT utricle. For the utricle, the dissected sensory epithelium is without anatomic landmarks, and therefore the angle values have been arbitrarily rotated to center the peak at $0^{\circ}$. For cristae, $0^{\circ}$ was set parallel to the direction of fluid flow in the semicircular canal. Histograms for two Fz3 - / ; Fz6 - / - cristae are shown to illustrate the phenotypic variability seen in hair bundle orientation. Using Fisher's exact test, the $p$ values for the pairwise comparisons of the distributions of hair bundle angles between genotypes are listed below. Utricle: $L p / L p$ versus WT, $8 \times 10^{-6}$; WT versus $F z 3-/-; F z 6-/-, 0.2 ; F z 3-/-; F z 6-/-$ versus $L p / L p, 4 \times 10^{-5}$. Cristae: $L p / L p$ versus WT, $1 \times 10^{-5} ;$ WT versus upper

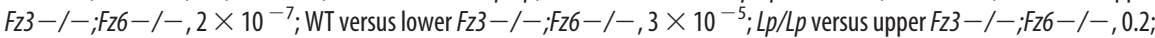
$L p / L p$ versus lower $F z 3-/-; F z 6-/-, 0.1$.

We note that the close proximity of sensory and nonsensory epithelial cells in the organ of Corti does not allow an unambiguous determination, at the light microscopic level, of which of two adjacent cells produces a given cell-surface protein that localizes to their common border. However, the distribution of knocked-in $\beta$-galactosidase expression (Fig. $5 A-D$ ) indicates that the $F z 3$ and $F z 6$ genes are expressed in all sensory hair cells, and therefore the immunostaining data imply that in the OHCs, the Fz3 and Fz6 proteins accumulate in the plasma membrane of sensory cells on the side of the cell opposite the kinocilium. Additional evidence favoring this conclusion was obtained by immunostaining the organ of Corti from WT:Fz6-/- chimeras and is described at the end of Results.

Among the irregular polygonal cells that tile the sensory epithelia of the utricle and cristae, Fz3 and Fz6 are concentrated on those cell faces that are approximately perpendicular to the global orientation of hair bundles (Fig. 6). The expression pattern for each $\mathrm{Fz}$ protein is similar across the sensory epithelium, with each epithelial cell, whether sensory or nonsensory, typically showing strong Fz3 and Fz6 immunostaining on approximately half of its sides and little or no staining on the other half. A similar immunolocalization pattern has been reported recently for Flamingo- 1 in the chicken inner ear (Davies et al., 2005). By the logic outlined above for the organ of Corti, we similarly infer, based on the ubiquitous $\beta$-galactosidase reporter expression in the vestibular sensory epithelia (Fig. $5 A, C$; and data not shown), that $F z 3$ and $F z 6$ are expressed in all of the sensory and supporting epithelial cells in the utricle, saccule, and cristae. Interestingly, in all of the innerear sensory epithelia, Fz3 immunostaining is more intense in Fz6-/- tissue relative to WT, and, reciprocally, Fz6 staining is more intense in $\mathrm{Fz} 3-\mathrm{I}-$ tissue relative to WT (Figs. 5, 6; and data not shown). This observation suggests that in the inner ear, Fz3 and Fz6 likely play interchangeable roles within the same macromolecular complexes such that a loss of one of them leads to a compensatory local accumulation of the other.

Fz3 and Fz6 proteins in the inner ear: apical localization

The cells that comprise inner-ear sensory epithelia are highly polarized along the apical-basal axis. It would therefore not be surprising if, in addition to segregation in the plane of the epithelium, Fz3 and Fz6 also showed apical/basal segregation. Immunostaining of the organ of Corti both in frozen vertical sections (Fig. 7A-D) and as a whole mount (Fig. $7 E-G$ ) shows that Fz3 and Fz6 are highly enriched near the apical face of the cell. In this location, junctional complexes between adjacent epithelial cells would be expected to limit lateral diffusion of integral membrane proteins and might contribute to the stability of signaling complexes. These observations support the general idea that there is an apical zone that is enriched for PCP components and through which PCP information is processed and relayed (Usui et al., 1999; Djiane et al., 2005). 
Fz3 and Fz6 protein localization in the inner ear: requirement for Vangl2

The similarity between $F z 3-/-$;Fz6-/and $L p / L p$ inner-ear and neural tube phenotypes and the accumulating evidence from Drosophila that many PCP gene products form a mutually interdependent complex led us to ask whether Fz3 and Fz6 protein localization is affected by loss of Vangl2 function. As seen in Figures 5 and 6, the localized Fz3 and Fz6 immunoreactivity characteristic of WT sensory epithelia is lost in the $L p / L p$ inner ear. A priori, this loss could arise from any of a variety of causes, including decreased $F z 3$ and Fz6 transcription, decreased mRNA or protein stability, or a dispersion of Fz3 and Fz6 proteins throughout the cell. To distinguish among these possibilities, we analyzed $F z 3$ and $F z 6$ transcripts by reverse transcriptase (RT)-PCR of WT versus Lp/Lp inner ears at E18 and Fz3 and Fz6 proteins by immunoblotting of detergent extracts from WT, Fz3-/-, Fz6-/-, and $L p / L p$ inner ears at E18. As seen in Figure $5 G$ (right pair of panels), the levels of Fz3 and Fz6 proteins in the $L p / L p$ samples are not altered relative to the WT control. Consistent with this observation, RT-PCR with serial dilutions of an E18 inner-ear cDNA template shows little or no difference in $F z 3$ and $F z 6$ transcript levels between WT and $L p / L p$ samples (data not shown). Thus, in the absence of Vangl2 function, Fz3 and Fz6 accumulate normally but fail to correctly assemble into a localized cell-surface complex.

\section{Absolute polarity of Fz6 protein determined in the crista using WT:Fz6-/- chimeras}

In Drosophila, genetic mosaics have been used extensively to study the local spread of PCP signaling near the boundary between mutant and WT tissue (Vinson and Adler, 1987, 2002; Strutt, 2003). This approach has recently been applied to the analysis of hair patterning in the mouse using WT:Fz6-/- embryo aggregation chimeras (Guo et al., 2004). Genetic mosaics have also been used in Drosophila to define which of two adjacent epithelial cells produces a particular protein that localizes to the boundary between them (Usui et al., 1999; Axelrod, 2001; Shimada et al., 2001; Strutt, 2001). Thus far, this second application of genetic mosaicism has not been reported in vertebrates.

In the experiment described below, we analyzed chimeras produced by aggregation of WT and $\mathrm{Fz} 6-/-$ embryos to determine (1) whether the Fz6 protein at the boundary between neighboring cells arises from synthesis in only one of the two neighbors and, if so, (2) how the pattern of asymmetric

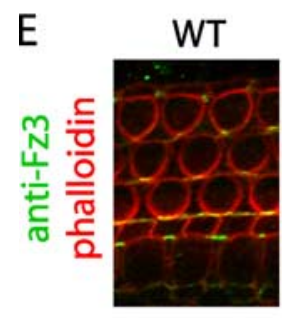

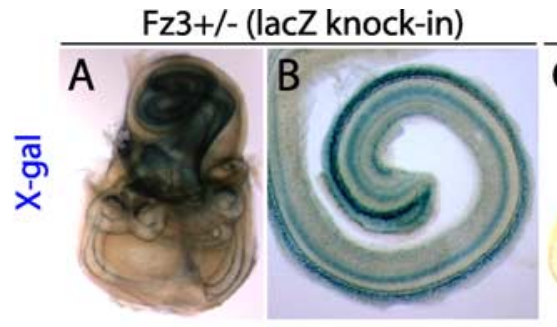
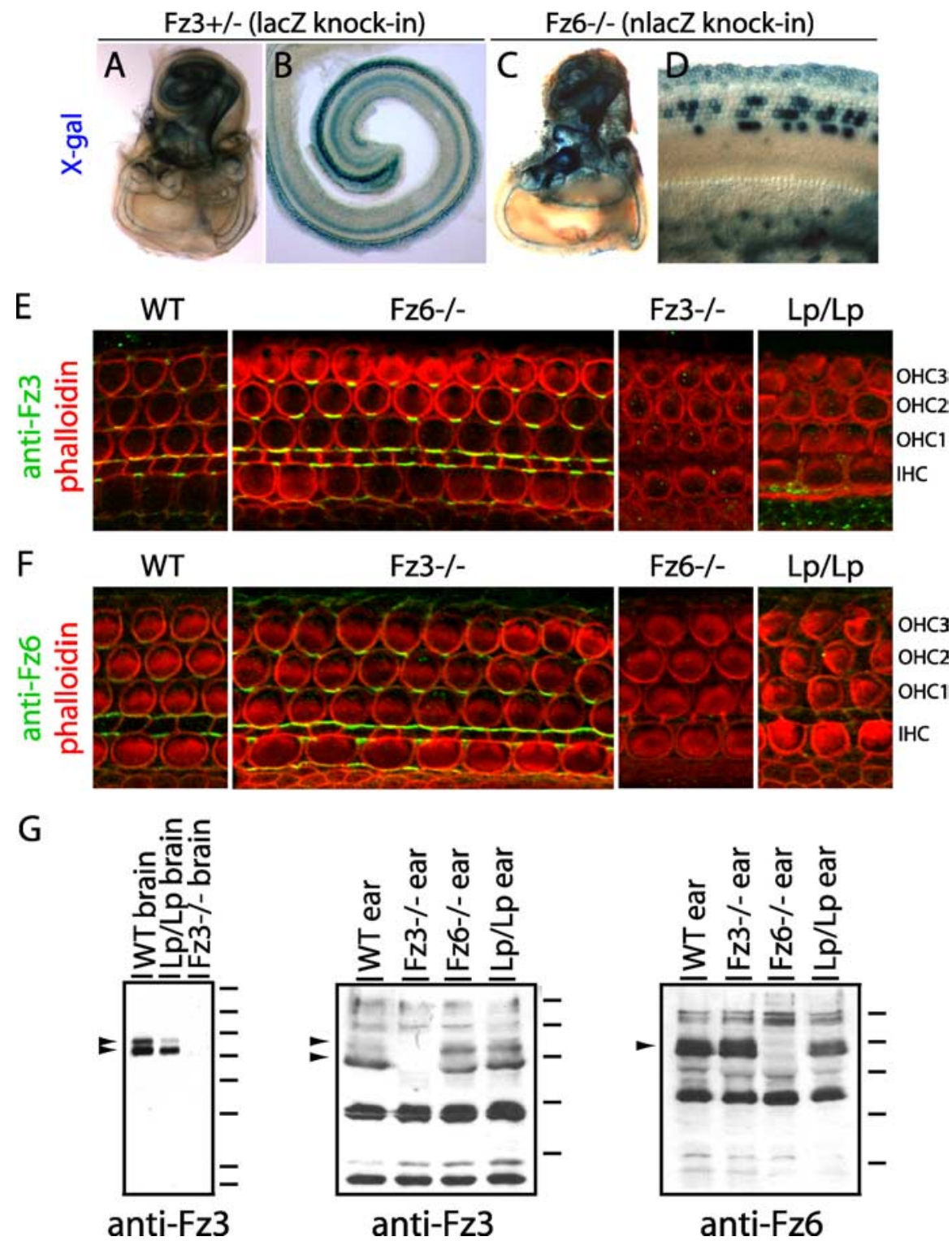

Figure 5. Asymmetric localization of $\mathrm{Fz} 3$ and $\mathrm{Fz} 6$ proteins in the organ of Corti and the effect of the $L p$ mutation. $A-D, X$-gal staining of the intact inner ear $(\boldsymbol{A}, \boldsymbol{C})$ and the dissected organ of $\operatorname{Corti}(\boldsymbol{B}, \boldsymbol{D})$ from Fz3 $+/-$ (lacZ knock-in) mice at E18 $(\boldsymbol{A}, \boldsymbol{B})$ or Fz6-/- (nuclear lacZ knock-in) mice at postnatal day 5 (P5) (C, D). In the images of the intact inner ear, the cochlea is at the top. For both genotypes, strong $X$-gal staining is seen in all of the sensory epithelia as well as in some of the adjacent nonsensory epthelia, including a thin band of cells running along each semicircular canal. As seen in $\boldsymbol{D}$, the nlacZ knock-in at the Fz6 locus shows variagated expression in the four rows of hair cells in the organ of Corti. $E$, $F$, Flat mounts of the organ of Corti showing immunolocalization of Fz3 and Fz6 in E18 WT, Fz3 - / - , and Lp/Lp samples; the Fz6 - / - sample is from P2. (Control experiments show identical Fz6 immunostaining patterns in WT samples at E18 and P2 but a greater $\mathrm{F} z 6$ intensity at P2.) The specificities of the Fz3 and $F z 6$ antibody staining are demonstrated by their absence in $F z 3-/-$ and $F z 6-/-$ tissue, respectively. Relative to WT tissue, $F_{26} 6-/-$ tissue shows increased $F_{z 3} 3$ immunostaining intensity, and Fz3 $-/-$ tissue shows increased $F_{26}$ immunostaining intensity. In $L p / L p$ tissue, localized Fz3 and Fz6 signals are absent or greatly reduced. G, Immunoblots of postnuclear supernatant proteins from E18 mouse brain (left) or E18 mouse inner ear (right) probed with anti-Fz3 or anti-Fz6 antibodies as indicated. The $\mathrm{Fz} 3$ and $\mathrm{Fz} 6$ protein bands are indicated by arrowheads; the $\mathrm{Fz} 3$ protein appears as a doublet. In the left panel, the $\mathrm{Fz} 3$ protein is seen in WT and $L p / L p$ brains and is absent, as expected, from the $F z 3-/-$ brain. We note that the lower level of Fz 3 protein in the $L p / L p$ brain may be secondary to the gross anatomic disruption that arises from the open neural tube, rather than reflecting a specific affect of Vangl2 on Fz3. In the two inner-ear immunoblots, several nonspecific bands are present and serve as internal controls for protein loading. Each $\mathrm{Fz}$ band is missing from the extract prepared from the corresponding homozygous mutant and is unaltered in the extract prepared from the $L p / L p$ mutant. Molecular mass markers from top to bottom are as follows: left, 220, $130,90,70,60,40,30$, and $20 \mathrm{kDa}$; right, $130,90,70,60$, and $40 \mathrm{kDa}$.

Fz6 localization correlates with the global axis of planar polarity within the sensory epithelium. In flat mounts of chimeric sensory epithelia, mutant cells were identified by immunostaining for the nuclear-localized $\beta$-galactosidase that is expressed from the Fz6 
A
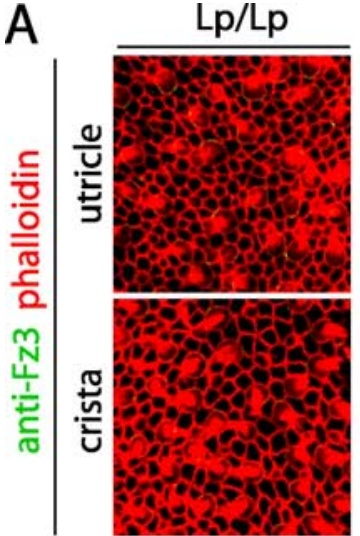

B

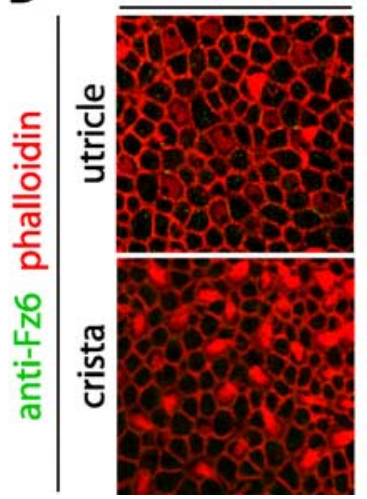

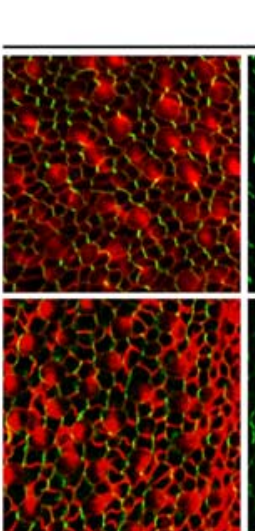

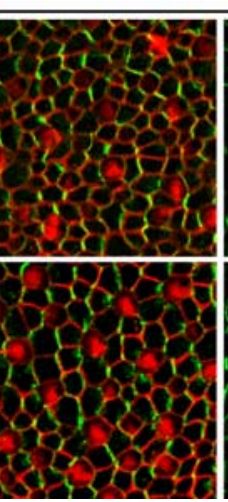

WT

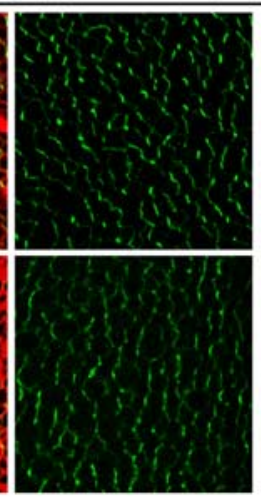

Fz3-/-

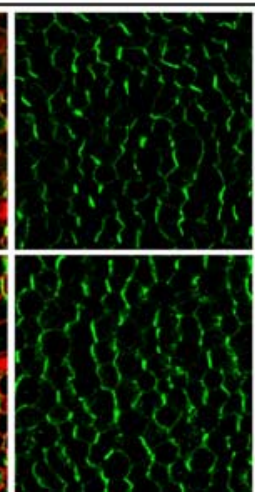

40 hair Fz3-positive unstained 30 bundles cell borders cell borders $\stackrel{8}{8} \mathrm{G}^{30}$

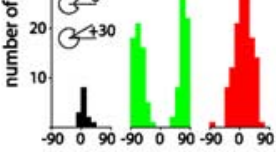
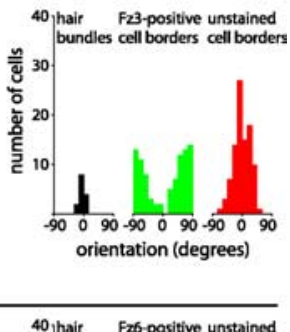
40 hair Fz6-positive unstained ¿ 30 bundles cell borders cell borders

\section{은}

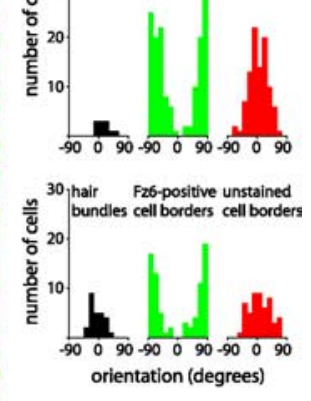

Figure 6. Asymmetric localization of $\mathrm{Fz} 3$ and $\mathrm{Fz} 6$ proteins in the $\mathrm{E} 18$ utricle and crista. $\boldsymbol{A}, \boldsymbol{B}$, Flat mounts of utricles and cristae showing phalloidin staining (red) and $\mathrm{Fz} 3(\boldsymbol{A})$ or $\mathrm{Fz} 6(\boldsymbol{B})$ immunolocalization (green). In each row, the rightmost pair of flat-mount images shows phalloidin plus anti-Fz immunostaining (left member of the pair) and the corresponding anti-Fz signal alone (right member of each pair). WT tissues show strong Fz3 immunostaining ( $\boldsymbol{A}$, right panels), but Fz6 immunostaining is substantially stronger in $\mathrm{Fz} 3-/-$ tissues compared with WT ( $\boldsymbol{B}$, right panels; and data not shown). The Fz3 and Fz6 proteins are preferentially localized to those sides of the polygonal epithelial cells that lie approximately at right angles to the hair bundle orientation, as quantitated in the histograms that accompany the WT and Fz3-/- flat mounts. Left, In Lp/Lp tissue, localized Fz3 and Fz6 immunostaining signals are absent or greatly reduced.

knock-out allele, cell boundaries were visualized with phalloidin, and Fz6 synthesized by WT cells was visualized with anti-Fz6 antibodies. As seen in the images in Figure $8 A-D$ of epithelial cells from the edge of a crista, Fz6 protein accumulates asymmetrically within the plane of the epithelium: at each interface between a WT cell and a Fz6-/- cell, Fz6 protein localizes to the cell-cell boundaries on the top left of the Fz6-/- cells and is missing from the boundaries on the bottom right of the Fz6-/- cells. When this polarity is compared with the polarity of the hair bundles within the same epithelial sheet, we observe that the face of the hair cell closest to the kinocilium corresponds to the face of each cell where Fz6 accumulates. This relationship appears to hold for all of the scorable boundaries between WT and Fz6-/cells within the sensory epithelium of the chimeric crista.

A similar analysis of the organ of Corti from WT:Fz6-/embryo chimeras confirms the general impression obtained from staining of nonchimeric tissue: Fz6 is produced autonomously within IHCs, OHCs, and supporting cells, and within each IHC and $\mathrm{OHC}$, the protein localizes to the inner face of the cell (Fig. $8 E, F)$. Interestingly, close inspection of Figure $8, E$ and $F$, shows punctate Fz6 immunoreactivity within WT cell bodies. Although low-intensity punctate signals are often dismissed as a nonspecific background, the absence of this signal in adjacent Fz6-/cells demonstrates that this signal is derived from Fz6 and may represent protein in intracellular vesicles. The variegation in orientation (degrees)

$\beta$-galactosidase expression in the $\mathrm{Fz}$-/organ of Corti (Fig. 5D) generates a subset of $F z 6-/-$ (nlacZ) cells that fail to stain with anti- $\beta$-galactosidase antibodies or with anti-Fz6. Two such cells are seen in Figure $8, E$ and $F$.

In contrast to the cristae, where Fz6 localizes on the side of the cell closest to the kinocilium, in the organ of Corti, Fz6 localizes on the side of the cell opposite the kinocilium. Although not demonstrated by mosaic analysis, we presume, based on the identical Fz3 and Fz6 immunostaining patterns and the functional redundancy of the $F z 3$ and $F z 6$ genes, that the same localization holds for Fz3. These data suggest that, depending on local context, PCP signals can be read out in different ways to direct a particular hair bundle orientation. This general idea has also been suggested to explain how an alternating PCP signal across intersegmental and/or compartmental boundaries could direct the uniform polarity of bristle growth in the Drosophila abdomen (Lawrence et al., 2002, 2004).

\section{Discussion}

\section{A unified view of PCP}

The results reported here support the view that vertebrates and invertebrates use similar molecular mechanisms to control a wide variety of PCP-dependent developmental processes. They also support an increasingly unified view of the role that PCP components and/or PCP signaling plays in mammalian development. In this still emerging picture, the phenotypes associated with defects in core PCP genes include neural tube closure, eyelid closure, the orientation of inner-ear sensory hair bundles, hair patterning, and several aspects of axonal growth and guidance (supplemental Table 1, available at www. jneurosci.org as supplemental material).

Among these processes, neural tube and eyelid closure both involve oriented proliferation and migration of epithelial sheets. PCP signaling could plausibly control these processes by programming the orientation of cells within the epithelial sheet, an idea consistent with the observation that the division planes in epithelial cells at the surface of zebrafish embryos are highly correlated with the direction of gastrulation movements (Gong et al., 2004). This idea is also consistent with experiments in Caenorhabditis elegans indicating that Wnt signaling plays a role in orienting the mitotic spindle during early cell divisions (Thorpe et al., 1997).

The work reported here strengthens an intriguing connection between mammalian PCP and some aspects of axonal growth and guidance, each of which is now known to be controlled by various homologs of core PCP genes. With respect to axonal growth and guidance, $\mathrm{Fz} 3-/-$ and Celsr3-/- mice show nearly identical defects in numerous axon tracts in the forebrain (Wang et al., 2002, 2006; Tissir et al., 2005), and Fz3-/- mice show defects in rostral pathfinding by spinal cord sensory axons (Lyuksyutova et al., 2003). With respect to PCP, both Celsr1 and Vangl2 mutant mice show defects in neural tube closure and in the orientation of 
hair bundles on inner-ear sensory cells (Greene et al., 1998; Murdoch et al., 2001; Curtin et al., 2003; Montcouquiol et al., 2003; present study), and Fz6 controls hair patterning in the skin (Guo et al., 2004). The open neural tube and hair bundle orientation defects described here in $\mathrm{Fz} 3-/$ -;Fz6-/- embryos provide the most direct evidence for a functional connection between PCP and axonal growth and guidance, because they demonstrate that a single protein, Fz3, is involved in both processes. It will be of great interest to determine the molecular mechanism(s) by which Fz3 and Celsr3 direct axonal growth and guidance.

\section{PCP and ciliated epithelial cells}

The precision with which hair bundles are oriented in auditory and vestibular sensory cells had made this process a prime candidate for PCP signaling even before the discovery of auditory hair bundle misorientation in Lp, Scribble, Celsr1, Dvl1/ Dvl2, PTK7, and Fz3/Fz6 mutant mice (Lewis and Davies, 2002). The present work extends the study of inner-ear PCP to the vestibular system and establishes the vestibular sensory epithelia as useful tissues for analyzing PCP. Interestingly, in both the utricle and saccule, the hair bundles reverse their orientations across an equator, a feature reminiscent of the reversal of ommatidial polarity on either side of the equator in the Drosophila eye.

In both auditory and vestibular hair cells, the asymmetric location of the kinocilium, the only true cilium in the hair bundle, immediately suggests that hair bundle orientation may be controlled by the location or orientation of the cilium in much the way that the planes of cell division reflect the location and orientation of the basal body. If this model is correct, it raises the question of how Fz3 and Fz6, and presumably other PCP proteins, on the lateral plasma membrane can signal over a distance of many hundreds of nanometers to a cilium embedded in the apical face of the cell.

The relationship between cilia/basal bodies and PCP suggested in the paragraphs above is further strengthened by a series of intriguing connections that have recently emerged between noncanonical Wnt signaling, the primary cilium/basal body in epithelial cells, left-right asymmetry, and directional growth and epithelial modeling in the kidney. In humans and mice, mutations in the Inversin gene, which codes for a cilium-associated protein, cause situs inversus and cystic defects in renal tubule development; in gastrulating Xenopus, Inversin is required for convergent extension, a process tied to noncanonical Wnt signaling; and in cell culture, Inversin interacts with and promotes the degradation of Disheveled (Otto et al., 2003; Simons et al., 2005). Most intriguingly, Inversin mutant mice have hair patterning defects similar to those observed in $\mathrm{Fz} 6-/-$ mice (Simons et al., cells and pillar cells.
WT
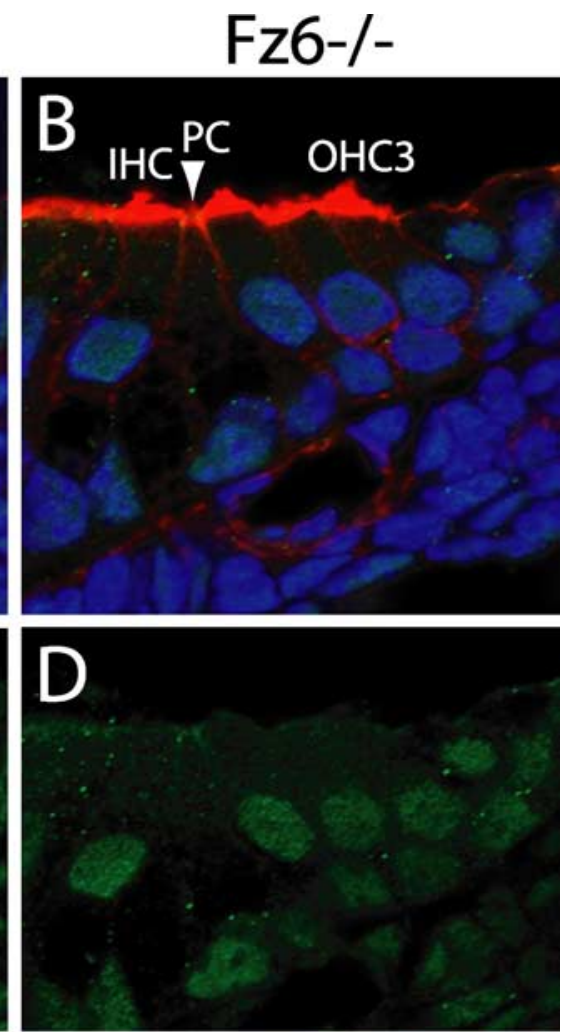

Figure 7. Apical localization of Fz proteins in the organ of Corti at postnatal day 0. A-D, Immunolocalization of Fz6 in frozen odies $(\boldsymbol{F})$ and the cuboidal pillar cells can be seen sandwiched between the $\mathrm{HC}$ (s and $\mathrm{OHC1}$ s. Fz3 is concentrated in the apical region $(\boldsymbol{F})$ of the hair

2005). Additional connections between PCP and ciliary function are also emerging from the study of Bardet-Biedl syndrome in humans and in the corresponding animal models (Ross et al., 2005).

\section{PCP in complex epithelia}

The striking asymmetry of Fz3 and Fz6 protein localization in auditory and vestibular sensory epithelia and the disruption of that localization in $L p / L p$ mutants supports the idea that mammalian PCP components are assembled into asymmetric cellsurface complexes in much the way that various PCP components assemble asymmetrically in the Drosophila wing. However, in contrast to the nearly crystalline monolayer of hexagonal epithelial cells that tile the Drosophila wing, sensory and supporting cells of diverse shape and size tile the mammalian auditory and vestibular epithelia. In the mouse inner ear, each of the vestibular sensory epithelia is tiled by an irregular mosaic of predominantly 
WT :Fz6-/- (nlacZ) chimeric crista

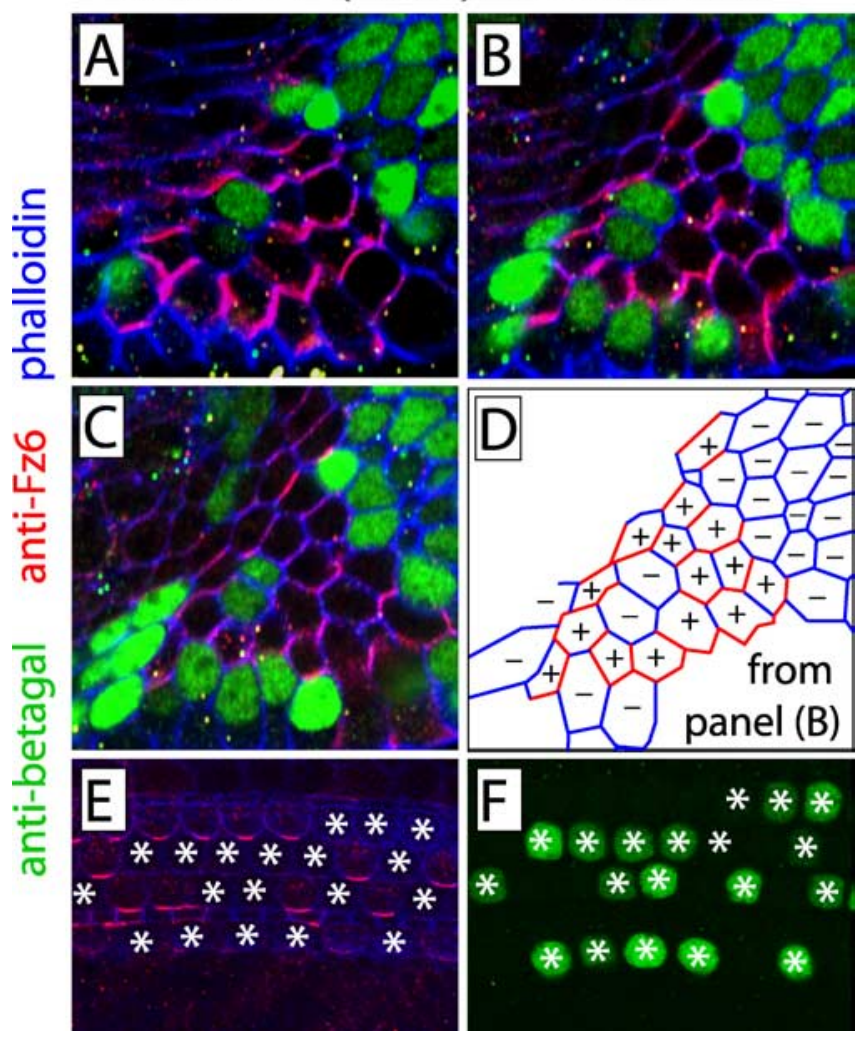

Figure 8. Absolute orientation of Fz6 accumulation determined using WT:Fz6-/- (nlacZ) chimeric sensory epithelia at postnatal day 2 (P2) to P3. A-C, Successive optical sections of a chimeric crista stained with anti- $\beta$-galactosidase (green; to visualize nuclear $\beta$-galactosidase in $F z 6-/-$ cells), anti-Fz6 (red; produced only by WT cells), and phalloidin (blue). D, Schematic of Fz6 and phalloidin labeling. The cell boundaries are derived from $\boldsymbol{B}$; the assignment of the presence (red) or absence (blue) of $\mathrm{Fz} 6$ labeling has been made with reference to all three optical sections $(\boldsymbol{A}-\boldsymbol{C})$ because the zones of most intense phalloidin or Fz6 labeling do not always reside within a single optical plane. Cells are scored as + for WT and - for $F z 6-/-$. The orientations of cell borders that display Fz6 labeling are approximately along a line from top right to bottom left. In regions where a Fz6 - I - cell abuts a WT cell, Fz6 protein is found on the top left side but not on the bottom right side of the Fz6 - / - cell, as seen for example, with the two adjacent $\mathrm{Fz} 6-1-$ cells in the center of image. $E, F$, Analogous flat mount of the organ of Corti in a WT:Fz6 $-/-$ (nlacZ) chimera. The asterisks denote the locations of Fz6- $/-$ (nlacZ) cell bodies, two of which exhibit the variegated absence of $\beta$-galactosidase expression illustrated in Figure 5D. The four rows of hair cell nuclei are several micrometers below the apical face of the epithelium (see Fig. 7), and they occupy a somewhat broader region when viewed as a flat mount (compare $\boldsymbol{E}, \boldsymbol{F}$ ). In the organ of Corti, Fz6 synthesized within each WT sensory cell localizes to only one lateral face of that cell; as expected, Fz6-/- cells lack Fz6 immunoreactivity.

pentagonal and hexagonal cells with sides of widely varying lengths. Intriguingly, the density of Fz3 and Fz6 proteins is nearly constant along any particular border between neighboring cells, with changes in density occurring abruptly where the border angle changes and contact begins with a different neighboring cell. These characteristics are in keeping with a model in which sideto-side contacts between components within a single cell, as well as contacts with components on the surface of the neighboring cell, reinforce a zipper-like assembly of cell-surface PCP complexes (Klein and Mlodzik, 2005). However, it remains to be established how exactly this or any other mechanism would operate in an irregular polygonal cell to assess the angle that each side presents relative to the global polarity vector and thereby to determine how much Fz3 or Fz6 protein should be displayed on that side.
The asymmetric localization of Fz3 and Fz6 proteins in both sensory and supporting cells demonstrates that, within the plane of the epithelium, supporting cells are molecularly asymmetric despite the lack of any apparent morphological asymmetry, such as an asymmetrically positioned cilium. These observations suggest that sensory hair cells, which rarely, if ever, contact one another directly, acquire polarity information from the immediately surrounding supporting cells and that this information is likely to be transmitted by and available to every cell in the epithelium. This phenomenon presumably occurs on an even larger scale in the skin where the angle that each hair follicle makes with the overlying epidermis must be coordinated with those of neighboring follicles many cell diameters away, a process that is partially disrupted in Fz6-/- mice (Guo et al., 2004). It will be of great interest to determine whether this coordination is effected by local signals, as observed in the Drosophila wing (Adler, 2002), by long-range gradients of one or more ligands, as suggested in the Drosophila abdomen and the mammalian spinal cord (Lawrence et al., 2002, 2004; Lyuksyutova et al., 2003), or by a combination of the two.

\section{References}

Adler PN (2002) Planar signaling and morphogenesis in Drosophila. Dev Cell 2:525-535.

Axelrod JD (2001) Unipolar membrane association of Dishevelled mediates Frizzled planar cell polarity signaling. Genes Dev 15:1182-1187.

Beall SA, Boekelheide K, Johnson KJ (2005) Hybrid GPCR/cadherin (Celsr) proteins in rat testis are expressed with cell type specificity and exhibit differential Sertoli cell-germ cell adhesion activity. J Androl 26:529-538.

Bhanot P, Brink M, Samos CH, Hsieh JC, Wang Y, Macke JP, Andrew D, Nathans J, Nusse R (1996) A new member of the frizzled family from Drosophila functions as a Wingless receptor. Nature 382:225-230.

Bhanot P, Fish M, Jemison JA, Nusse R, Nathans J, Cadigan KM (1999) Frizzled and Dfrizzled-2 function as redundant receptors for Wingless during Drosophila embryonic development. Development 126:4175-4186.

Chen CM, Struhl G (1999) Wingless transduction by the Frizzled and Frizzled2 proteins of Drosophila. Development 126:5441-5452.

Copp AJ, Greene NDE, Murdoch JN (2003) The genetic basis of mammalian neurulation. Nat Rev Genet 4:784-793.

Curtin JA, Quint E, Tsipouri V, Arkell RM, Cattanach B, Copp AJ, Henderson DJ, Spurr N, Stanier P, Fisher EM, Nolan PM, Steel KP, Brown SD, Gray IC, Murdoch JN (2003) Mutation of Celsrl disrupts planar polarity of inner ear hair cells and causes severe neural tube defects in the mouse. Curr Biol 13:1129-1133.

Dabdoub A, Kelley MW (2005) Planar cell polarity and a potential role for a Wnt morphogen gradient in stereociliary bundle orientation in the mammalian inner ear. J Neurobiol 64:446-457.

Dabdoub A, Donohue MJ, Brennan A, Wolf V, Montcouquiol M, Sassoon DA, Hseih JC, Rubin JS, Salinas PC, Kelley MW (2003) Wnt signaling mediates reorientation of outer hair cell stereociliary bundles in the mammalian cochlea. Development 130:2375-2384.

Davies A, Formstone C, Mason I, Lewis J (2005) Planar polarity of hair cells in the chick inner ear is correlated with polarized distribution of c-flamingo-1 protein. Dev Dyn 233:998-1005.

Denman-Johnson K, Forge A (1999) Establishment of hair bundle polarity and orientation in the developing vestibular system of the mouse. J Neurocytol 28:821-835.

Djiane A, Yogev S, Mlodzik M (2005) The apical determinants aPKC and dPatj regulate Frizzled-dependent planar cell polarity in the Drosophila eye. Cell 121:621-631.

Findlater GS, McDougall RD, Kaufman MH (1993) Eyelid development, fusion and subsequent reopening in the mouse. J Anat 183:121-129.

Gong Y, Mo C, Fraser SE (2004) Planar cell polarity signalling controls cell division orientation during zebrafish gastrulation. Nature 430:689-693.

Greene ND, Gerrelli D, Van Straaten HW, Copp AJ (1998) Abnormalities of floor plate, notochord and somite differentiation in the loop-tail (Lp) mouse, a model of severe neural tube defects. Mech Dev 73:59-72.

Gubb D, Garcia-Bellido A (1982) A genetic analysis of the determination of 
cuticular polarity during development in Drosophila melanogaster. J Embryol Exp Morphol 68:37-57.

Guo N, Hawkins C, Nathans J (2004) Frizzled6 controls hair patterning in mice. Proc Natl Acad Sci USA 101:9277-9281.

Hamblet NS, Lijam N, Ruiz-Lozano P, Wang J, Yang Y, Luo Z, Mei L, Chien KR, Sussman DJ, Wynshaw-Boris A (2002) Dishevelled 2 is essential for cardiac outflow tract development, somite segmentation and neural tube closure. Development 129:5827-5838.

Ishikawa T, Tamai Y, Zorn AM, Yoshida H, Seldin MF, Nishikawa S, Taketo MM (2001) Mouse Wnt receptor gene Fzd5 is essential for yolk sac and placental angiogenesis. Development 128:25-33.

Kennerdell JR, Carthew RW (1998) Use of dsRNA-mediated genetic interference to demonstrate that frizzled and frizzled 2 act in the wingless pathway. Cell 95:1017-1026.

Kibar Z, Vogan KJ, Groulx N, Justice MJ, Underhill DA, Gros P (2001) Ltap, a mammalian homolog of Drosophila Strabismus/Van Gogh, is altered in the mouse neural tube mutant Loop-tail. Nat Genet 28:251-255.

Klein TJ, Mlodzik M (2005) Planar cell polarization, an emerging model points in the right direction. Annu Rev Cell Dev Biol 21:155-176.

Lawrence PA, Casal J, Struhl G (2002) Towards a model of the organisation of planar polarity and pattern in the Drosophila abdomen. Development 129:2749-2760.

Lawrence PA, Casal J, Struhl G (2004) Cell interactions and planar polarity in the abdominal epidermis of Drosophila. Development 131:4651-4664.

Lewis J, Davies A (2002) Planar cell polarity in the inner ear, how do hair cells acquire their oriented structure? J Neurobiol 53:190-201.

Logan CY, Nusse R (2004) The Wnt signaling pathway in development and disease. Annu Rev Cell Dev Biol 20:781-810.

Lu X, Borchers AG, Jolicoeur C, Rayburn H, Baker JC, Tessier-Lavigne M (2004) PTK7/CCK-4 is a novel regulator of planar cell polarity in vertebrates. Nature 430:93-98.

Lyuksyutova AI, Lu C-C, Milanesio N, King LA, Guo N, Wang Y, Nathans J, Tessier-Lavigne M, Zuo Y (2003) Anterior turning of commissural axons after midline crossing guided by Wnt/Frizzled signaling. Science 302:1984-1988.

Montcouquiol M, Rachel RA, Lanford PJ, Copeland NG, Jenkins NA, Kelley MW (2003) Identification of Vangl2 and Scrb1 as planar polarity genes in mammals. Nature 423:173-177.

Murdoch JN, Doudney K, Paternotte C, Copp AJ, Stanier P (2001) Severe neural tube defects in the loop-tail mouse result from mutation of Lpp1, a novel gene involved in floor plate specification. Hum Mol Genet 10:2593-2601.

Murdoch JN, Henderson DJ, Doudney K, Gaston-Massuet C, Phillips HM, Paternotte C, Arkell R, Stanier P, Copp AJ (2003) Disruption of scribble (Scrb1) causes severe neural tube defects in the circletail mouse. Hum Mol Genet 12:87-98.

Otto EA, Schermer B, Obara T, O’Toole JF, Hiller KS, Mueller AM, Ruf RG, Hoefele J, Beekmann F, Landau D, Foreman JW, Goodship JA, Strachan T, Kispert A, Wolf MT, Gagnadoux MF, Nivet H, Antignac C, Walz G, Drummond IA, et al. (2003) Mutations in INVS encoding inversin cause nephronophthisis type 2, linking renal cystic disease to the function of primary cilia and left-right axis determination. Nat Genet 34:413-420.

Ross AJ, May-Simera H, Eichers ER, Kai M, Hill J, Jagger DJ, Leitch CC, Chapple JP, Munro PM, Fisher S, Tan PL, Phillips HM, Leroux MR, Henderson DJ, Murdoch JN, Copp AJ, Eliot MM, Lupski JR, Kemp DT, Dollfus H, et al. (2005) Disruption of Bardet-Biedl syndrome ciliary proteins perturbs planar cell polarity in vertebrates. Nat Genet 37:1135-1140.

Shimada Y, Usui T, Yanagawa S, Takeichi M, Uemura T (2001) Asymmetric localization of Flamingo, a seven-pass transmembrane cadherin, and Disheveled in planar cell polarization. Curr Biol 11:859-863.

Simons M, Gloy J, Ganner A, Bullerkotte A, Bashkurov M, Kronig C, Schermer B, Benzing T, Cabello OA, Jenny A, Mlodzik M, Polok B, Driever W, Obara T, Walz G (2005) Inversin, the gene product mutated in nephronophthisis type II, functions as a molecular switch between Wnt signaling pathways. Nat Genet 37:537-543.

Strong LC, Hollander WF (1949) Hereditary looptail in the house mouse accompanied by imperforate vagina and with lethal craniorachischisis when homozygous. J Hered 40:329-334.

Strutt D (2001) Asymmetric localization of frizzled and the establishment of polarity in the Drosophila wing. Mol Cell 7:367-375.

Strutt D (2003) Frizzled signaling and cell polarization in Drosophila and vertebrates. Development 130:4501-4513.

Thorpe CJ, Schlesinger A, Carter JC, Bowerman B (1997) Wnt signaling polarizes an early C. elegans blastomere to distinguish endoderm from mesoderm. Cell 90:695-705.

Tissir F, Bar I, Jossin Y, Goffinet AM (2005) Protocadherin Celsr3 is crucial in axonal tract development. Nat Neurosci 8:451-457.

Torban E, Kor C, Gros P (2004) Van Gogh-like2 (Strabismus) and its role in planar cell polarity and convergent extension in vertebrates. Trends Genet 20:570-577.

Usui T, Shima Y, Shimada Y, Hirano S, Burgess RW, Schwarz TL, Takeichi M, Uemura T (1999) Flamingo, a seven-pass transmembrane cadherin, regulates planar cell polarity under the control of Frizzled. Cell 98:585-595.

van Es JH, Jay P, Gregorieff A, van Gijn ME, Jonkheer S, Hatzis P, Thiele A, van den Born M, Begthel H, Brabletz T, Taketo MM, Clevers H (2005) Wnt signalling induces maturation of Paneth cells in intestinal crypts. Nat Cell Biol 7:381-386.

Vinson CR, Adler PN (1987) Directional non-cell autonomy and the transmission of polarity information by the frizzled gene of Drosophila. Nature 329:549-551.

Vinson CR, Conover S, Adler PN (1989) A Drosophila tissue polarity locus encodes a protein containing seven potential transmembrane domains. Nature 338:263-264.

Wang J, Mark S, Zhang X, Qian D, Yoo SJ, Radde-Gallwitz K, Zhang Y, Lin X, Collazo A, Wynshaw-Boris A, Chen P (2005) Regulation of polarized extension and planar cell polarity in the cochlea by the vertebrate PCP pathway. Nat Genet 37:980-985.

Wang Y, Macke JP, Abella BS, Andreasson K, Worley P, Gilbert DJ, Copeland NG, Jenkins NA, Nathans J (1996) A large family of putative transmembrane receptors homologous to the product of the Drosophila tissue polarity gene frizzled. J Biol Chem 271:4468-4476.

Wang Y, Huso D, Cahill H, Ryugo D, Nathans J (2001) Progressive cerebellar, auditory, and esophageal dysfunction caused by targeted disruption of the frizzled-4 gene. J Neurosci 21:4761-4771.

Wang Y, Thekdi N, Smallwood PM, Macke JP, Nathans J (2002) Frizzled-3 is required for the development of major fiber tracts in the rostral CNS. J Neurosci 22:8563-8573.

Wang Y, Zhang J, Mori S, Nathans J (2006) Axonal growth and guidance defects in Frizzled3 knockout mice: a comparison of diffusion tensor magnetic resonance imaging, neurofilament staining, and genetically directed cell labeling. J Neurosci 26:355-364.

Xu Q, Wang Y, Dabdoub A, Smallwood PM, Williams J, Woods C, Kelley MW, Jiang L, Tasman W, Zhang K, Nathans J (2004) Vascular development in the retina and inner ear: control by Norrin and Frizzled-4, a high-affinity ligand-receptor pair. Cell 116:883-895. 